\title{
Total mesorectal excision for rectal cancer in an unselected population: quality assessment in a low volume center
}

\author{
Floris T. J. Ferenschild • Imro Dawson • \\ Johannes H. W. de Wilt • Eelco J. R. de Graaf • \\ Richard P. R. Groenendijk - Geert W. M. Tetteroo
}

Accepted: 13 May 2009 /Published online: 2 June 2009

(C) The Author(s) 2009. This article is published with open access at Springerlink.com

\begin{abstract}
Objective The aim of this study was to review the results and long-term outcome after total mesorectal excision (TME) for adenocarcinoma of the rectum in an unselected population in a community teaching hospital.

Materials and methods Between 1996 and 2003, 210 patients with rectal cancer were identified in our prospective database, containing patient characteristics, radiotherapy plans, operation notes, histopathological reports, and follow-up details. An evaluation of prognostic factors for local recurrence, distant metastases, and overall survival was performed.

Results The mean age at diagnosis was 69 years (range 4091 years). A total of 145 patients were treated by anterior rectal resection; 65 patients had to undergo an abdominoperineal resection (APR). Anastomotic leakage rate was $5 \%$. Postoperative mortality was 3\%. After a median follow-up of 3.6 years, the local recurrence-free rate in patients with microscopically complete resections was $91 \%$. The 5-year overall survival rate was $58 \%$. An increased serum carcinoembryonic antigen, an APR, positive lymph nodes, and an incomplete resection all significantly influenced the 5-year overall survival and local recurrence rate. In a multivariate analysis, age was the most important prognostic factor for overall survival.
\end{abstract}

F. T. J. Ferenschild • I. Dawson • E. J. R. de Graaf •

R. P. R. Groenendijk · G. W. M. Tetteroo $(\bowtie)$

Department of Surgery, IJsselland Hospital,

P.O. Box 690, 2900 AR Capelle aan den IJssel, The Netherlands

e-mail: gtetteroo@ysl.nl

J. H. W. de Wilt

Department of Surgical Oncology,

Erasmus MC-Daniel den Hoed Cancer Center,

Rotterdam, The Netherlands
Conclusions Patients with rectal cancer can safely be treated with TME in a community teaching hospital and leads to a good overall survival and an excellent local control. In patients aged above 80, treatment-related mortality is an important competitive risk factor, which obscures the positive effect of modern rectal cancer treatment.

Keywords TME Local recurrence $\cdot$ Rectal cancer . Carcinoma $\cdot$ Radiotherapy $\cdot$ CEA

$\begin{array}{ll}\text { Abbreviations } \\ \text { TME } & \text { total mesorectal excision } \\ \text { LAR } & \text { low anterior resection } \\ \text { APR } & \text { abdominoperineal resection } \\ \text { TEM } & \text { transanal endoscopic microsurgery } \\ \text { EBRT } & \text { external beam radiation therapy } \\ \text { CEA } & \text { carcinoembryonic antigen } \\ \text { CT } & \text { computed tomography } \\ \text { MRI } & \text { magnetic resonance imaging } \\ \text { AJCC } & \text { American Joint Committee of Cancer } \\ \text { TNM } & \text { tumor node metastases }\end{array}$

\section{Introduction}

The ultimate goal in the treatment of rectal cancer is to maximize local control and to improve overall long-term survival. Local recurrence is a serious problem in the treatment of rectal cancer, since it causes disabling symptoms and is difficult to treat; besides, it is thought to be an important factor in overall long-term survival. After conventional surgery, a high incidence of local recurrence of up to $40 \%$ was reported $[1,2]$. Heald described a new 
concept in operative anatomy, the total mesorectal excision (TME) technique in which the entire mesorectum is enveloped and resected [3-5]. The introduction of this surgical technique resulted in a local recurrence rate of $<10 \%$ in specialized centers. It was recognized that the involvement of the circumferential margin by tumor cells is predictive for local recurrences [6]. With this new standardized technique, a unique chance was given to study the effect of (neo)adjuvant therapy. Based on the good results of preoperative radiotherapy in Sweden [7], the Dutch Colorectal Cancer Group started a randomized multicenter trial. They investigated whether the addition of preoperative radiotherapy increases the benefit of TME [8-10]. The outcome of this study showed a significant reduction in local recurrences with preoperative radiation compared to operation alone in patients with rectal cancer (5.6\% versus $10.2 \%$ at 6.1 years) [11]. Differences were not significant for tumors in the upper third of the rectum. Therefore, from the year 2001 onwards, the Comprehensive Cancer Centre Rotterdam decided to standardize preoperative radiotherapy for each patient with a tumor up to $10 \mathrm{~cm}$ from the anal verge. A course of $5 \times 5$ Gy was given to all these patients. However, the TME study was performed in selected patients under optimal conditions and low volume centers still report higher recurrence rates $[12,13]$.

This study was designed to assess the outcome after treatment of primary rectal cancer in a community teaching hospital with special emphasis on local recurrence and overall survival.

\section{Materials and methods}

Patients and preoperative assessment

Between 1996 and 2003, the hospital charts of 210 patients with primary rectal cancer were recorded in our prospective database. Medical records were examined to obtain all necessary data. All patients had histologically proven adenocarcinoma of the rectum without evidence of distant metastases at that stage. The inferior margin of the tumor was located not further than $15 \mathrm{~cm}$ from the anal verge to be defined as a rectal tumor. Prior to surgery, medical history, physical examination, and routine blood tests were assessed. Work-up consisted of colonoscopy with biopsy, followed by an X-ray of the chest in combination with abdominal ultrasound to exclude distant metastases. In most cases, a computed tomography (CT) scan of the abdomen was also made. In selected cases, especially to rule out the suspicion of invasion of the tumor into adjacent organs, a magnetic resonance imaging (MRI) of the pelvis was made. Our database consists of hospital notes, radiotherapy plans, operation notes, and histopathological reports to obtain the following information: demographics, preoperative diag- nostic intervention, tumor staging, radiotherapy technique, surgical details, histopathological details, and complications. Follow-up was registered using hospital notes, medical letters, and in some cases, by general practitioner information.

\section{External beam radiation therapy}

Starting in 2001, short-term external beam radiation therapy (EBRT) was given to all patients with a tumor up to $10 \mathrm{~cm}$ [8]. A radiation dose of 25 Gy in five daily fractions was delivered. In patients with a locally advanced tumor, $50 \mathrm{~Gy}$ radiotherapy was given in 25 daily fractions of 2 Gy. Locally advanced tumor growth was defined as infiltration of the tumor in the environment and/or pathologically enlarged lymph nodes near the circumferential margins of the mesorectum on a CT scan. Afterwards, an evaluation of the effect of radiation therapy was done again by CT scan. When thought feasible, an explorative laparotomy was done with the intention to do a resection. EBRT was administered by a three-field technique, using one posterior and two lateral ports.

\section{Surgery}

All patients underwent surgery according to the TME principle, as advocated by Heald [3]. In patients with a high rectal cancer, the mesorectum was divided $5 \mathrm{~cm}$ below the tumor and a partial mesorectal excision was performed. Surgery was planned 3-5 days after short-term radiotherapy. For locally advanced or T4 tumors, reevaluation was done after irradiation. When feasible, the patient was operated on 5-6 weeks later. Prophylactic intravenous antibiotics were given at the induction of anesthesia in all patients. Three well-trained TME surgeons performed all operations. In case of an anterior resection, a side to end anastomosis was made using the double stapling technique. A diversion stoma was made in case of complicated procedures, a positive leakage test, or incomplete doughnuts. Loop ileostomy was the preferred method in these cases. In case of a positive leakage test, the leakage was localized and sutured when discovered.

\section{Pathology}

The pathologists were trained to identify Circumferential Resection Margin (CRM), positive nodes, and lateral spread of tumor according to the protocol of Quirke et al. [14].

\section{Adjuvant therapy}

Generally, patients were not treated with adjuvant chemotherapy, irrespective of nodal status. After 2005, there was a 
tendency to give adjuvant chemotherapy in wellconditioned patients with positive lymph nodes.

\section{Statistics}

Local control and overall survival curves were calculated from the time of TME and were based on the method of Kaplan and Meier. All statistical analyses were executed in SPSS. Univariate comparisons of survival end points were calculated using the log-rank test. Significance was defined as $P<0.05$. For multivariate analysis, Cox regression was used to evaluate prognostic factors.

\section{Results}

Patients

A total of 210 patients were operated on with curative intent. One hundred thirteen (54\%) of the patients were male and 97 (46\%) were female with a median age of 70 years (range 40-90 years) The median level of preoperative CEA was 2.8 (range 0.2-142). Preoperative characteristics are shown in Table 1. Fifty-three patients $(25 \%)$ received preoperative radiotherapy. The majority of these patients $(n=42)$ received short-term radiotherapy. Eleven patients were treated with 50 Gy external beam radiation therapy because of preoperatively defined locally advanced tumors. Since 2001, due to changing policy in preoperative radiotherapy, a growing amount of patients received EBRT. Of the 40 patients (with a tumor below $10 \mathrm{~cm}$ ) included in this study from 2001, 36 received shortterm radiotherapy.

Surgical results

A low anterior resection (LAR) was done in 145 patients (69\%) and an abdominoperineal resection (APR) in 65

Table 1 Preoperative characteristics

\begin{tabular}{lll}
\hline & Total & Percentage \\
\hline Symptoms & & \\
$\quad$ Blood loss & 153 & 73 \\
Mucus & 38 & 18 \\
Tenesmus & 47 & 22 \\
Diarrhea & 44 & 21 \\
Constipation & 35 & 17 \\
Distance of tumor from anal verge $(\mathrm{cm})$ & & \\
$\leq 5$ & 59 & 28 \\
$5-10$ & 87 & 41 \\
$10-15$ & 64 & 31 \\
\hline
\end{tabular}

Table 2 Postoperative complications and reinterventions

\begin{tabular}{lll}
\hline & Total & Percentage \\
\hline Minor complications & 16 & 8 \\
$\quad$ Urinary infection & 3 & 1 \\
Bladder retention & 17 & 8 \\
$\quad$ Wound infection abdominal & & \\
Major complications & 12 & $18^{\mathrm{a}}$ \\
Wound infection perineal & 8 & 5 \\
Anastomotic leakage & 3 & 1 \\
Intra-abdominal fluid collection without leak & & \\
Reintervention & 3 & 1 \\
Abscess drainage & 12 & 6 \\
Relaparotomy & 7 & 3 \\
Permanent colostomy & 2 & 1 \\
Permanent ileostomy & 3 & 1 \\
Temporary ileostomy & & \\
\hline
\end{tabular}

${ }^{\mathrm{a}} 18 \%$ of 65 APRs

patients (31\%). Of the 145 patients with a LAR, a diverting stoma was made in 26 patients $(18 \%)$, which was closed in 18 patients. Five patients underwent a local excision of the tumor (transanal endoscopic microsurgery [TEM]) as initial treatment before TME was performed. Thirteen patients (6\%) proved to have hepatic metastases during surgery. In ten of these patients, hepatic metastases were not diagnosed by ultrasonography or CT during the preoperative work-up, but discovered during surgery. In the other three patients, liver metastases were calculated and operated on during a second time. The median duration of surgery was $110 \mathrm{~min}$ (range 45-210 $\mathrm{min}$ ) and the median operative blood loss was $600 \mathrm{~mL}$ (range 50-4,000 mL). The median blood loss was significantly lower in LAR compared to APR, 400 versus $1,000 \mathrm{~mL}$, respectively $(P<0.001)$.

Complications are depicted in Table 2. Postoperative mortality was $3 \%(n=6)$. Twelve patients underwent a relaparotomy because of abdominal symptoms. During operation, an anastomotic leakage was found in eight patients; three patients were treated with a loop ileostomy and, in five patients, a colostomy was performed after the removal of the anastomosis. A reanastomosis was performed, after 6 and 9 months, in two of these patients. Perineal infections were present in 12 patients (18\%) after an APR and treated conservatively. All these 12 patients had been treated with preoperative radiotherapy.

Pathology

In 199 patients (95\%), a microscopic complete resection was performed (R0). In 11 (5\%) patients, the resection was microscopically incomplete (R1) including four patients 
Table 3 Pathology

\begin{tabular}{lll}
\hline & Total & Percentage \\
\hline Residual tumor & & \\
R0 & 199 & 95 \\
R1 & 11 & 58 \\
AJCC pTNM stage & & \\
CIS & 3 & 1 \\
I & 67 & 33 \\
II & 53 & 25 \\
III & 74 & 35 \\
IV & 13 & 6 \\
\hline
\end{tabular}

with a pT4 tumor. In five patients, incompleteness was related to the distal margin and in six patients because of an incomplete CRM. The postoperative tumor stage is given in Table 3. Two patients had no residual disease after TME. However, these patients had undergone a TEM before TME. TME was performed because the local excision was irradical on pathology. One of these patients had a T1 and one a T2 tumor at the initial pathology. Three patients had a carcinoma in situ. A T1 tumor was seen in 23 patients, a T2 in 63, a T3 in 106, and a T4 tumor in 15 patients. One hundred twentyeight patients were node-negative, 45 had metastasis in one to three regional lymph nodes (N1), and 37 had metastasis in four or more regional lymph nodes (N2).

Follow-up

The median follow-up was 3.6 years (range $0.4-8.4$ years). In total, 21 patients developed a local recurrence, most of them (83\%) discovered during the first 2 years of follow-up. Fourteen of 199 patients with a complete resection developed a local recurrence $(7 \%)$. Seven of 11 patients with an incomplete resection developed a local recurrence (64\%). A complete resection versus an incomplete resection was of significant importance on local control $(P<0.001$; Fig. 1). The actuarial overall 3- and 5-year local control rates were $92 \%$ and $88 \%$, respectively. Nineteen of the local recurrences

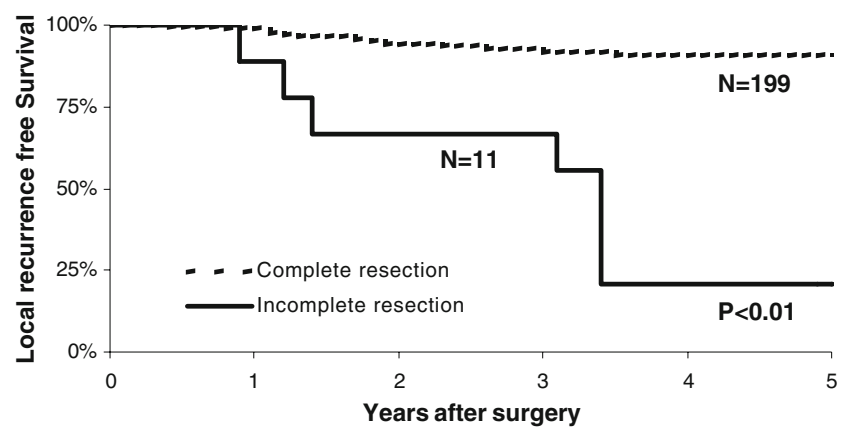

Fig. 1 Local recurrence according to a complete versus an incomplete resection $(P<0.01)$ were found in tumors primary located in the lowest two thirds of the rectum. A high level of CEA $(>5)$, an APR (Fig. 2), positive lymph nodes, and an incomplete resection negatively influenced the local recurrence rate significantly. There was no significant difference in age, gender, and preoperative radiotherapy regarding local recurrence (see Table 4). The significant prognostic factors were entered in a multivariate analysis (see Table 5). The most important factor was completeness of the resection. CEA in this multivariate analysis was not of significant importance anymore.

\section{Distant metastases}

Forty-five patients developed distant metastases, of which $40 \%$ was discovered during the first year of follow-up. Thirty-four patients developed hepatic metastases, 18 lung metastases, and five bone metastases. Lung and/or bone metastases were in $38 \%$ synchronic with hepatic metastases.

Overall survival

The actuarial overall 3- and 5-year survival rates were 72\% and $58 \%$, respectively. The 5 -year overall survival demonstrated a statistically significant difference between the pathological TNM (pTNM) stages, type of resection, lymph nodes, CEA levels (Fig. 3), age, and completeness of the resection (see Table 4). Patient's gender and preoperative radiotherapy were not of statistic significance. Increased age, advanced $\mathrm{T}$ stage, positive lymph node status, increased CEA, and completeness of the resection were independent risk factors for overall survival in the multivariate analysis (see Table 5). In a Cox regression model, age was the most important factor.

\section{Discussion}

Since the introduction of TME as the standard operative technique, the rate of local recurrence after resection of

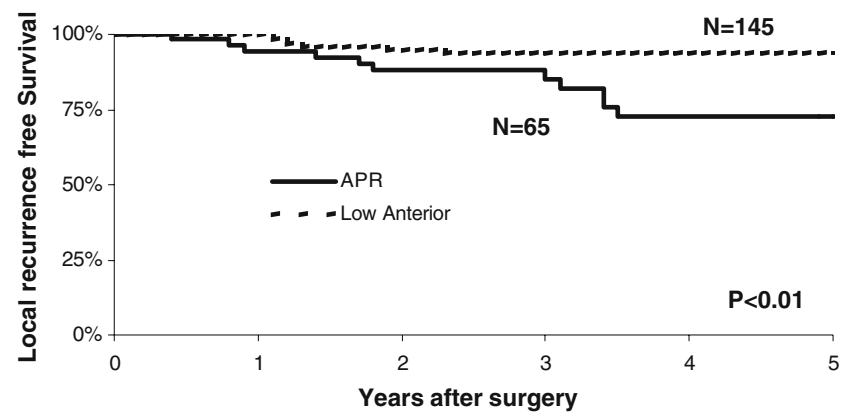

Fig. 2 Local recurrence according to type of resection $(P<0.01)$ 
Table 4 Univariate analysis on 5-year local recurrence-free (LRF) and overall survival (OS)

\begin{tabular}{|c|c|c|c|c|c|}
\hline & Number & LRF (\%) & $P$ value & OS $(\%)$ & $P$ value \\
\hline Radiotherapy & & & 0.32 & & 0.17 \\
\hline Yes & 53 & 82 & & 67 & \\
\hline No & 157 & 93 & & 55 & \\
\hline \multicolumn{6}{|l|}{ Type of resection } \\
\hline LAR & 145 & 93 & $<0.01$ & 61 & 0.02 \\
\hline APR & 65 & 63 & & 50 & \\
\hline CEA & & & 0.05 & & 0.04 \\
\hline$<5$ & 151 & 90 & & 65 & \\
\hline$>5$ & 59 & 65 & & 48 & \\
\hline Male & 114 & 90 & 0.55 & 57 & 0.60 \\
\hline Female & 96 & 85 & & 55 & \\
\hline Age & & & 0.36 & & $<0.01$ \\
\hline$<80$ & 173 & 85 & & 64 & \\
\hline$>80$ & 37 & 75 & & 30 & \\
\hline Node & & & $<0.01$ & & 0.01 \\
\hline Negative & 82 & 93 & & 65 & \\
\hline Positive & 128 & 79 & & 34 & \\
\hline \multicolumn{6}{|l|}{ Extent of resection } \\
\hline Complete & 199 & 92 & $<0.01$ & 62 & 0.05 \\
\hline Incomplete & 11 & 20 & & 17 & \\
\hline Tumor height (cm) & & & 0.11 & & 0.23 \\
\hline $0-5$ & 59 & 82 & & 52 & \\
\hline $5-10$ & 87 & 85 & & 56 & \\
\hline $10-15$ & 64 & 95 & & 65 & \\
\hline
\end{tabular}

rectal carcinomas spectacularly decreased from $37 \%$ in the early 1980 s after conventional surgery to $<10 \%$ at present [5]. TME provides sharp meticulous dissection to keep the visceral layer of the pelvic fascia intact and this is important to avoid breach in the mesorectum, which is now an important cause for local recurrence [15-18]. Neoadjuvant radiotherapy demonstrated to improve the TME results with a decreased local recurrence rate, but without an impact on survival [11]. In the present study, this impact of radiotherapy on local recurrence was not demonstrated, but the number of patients is small.

To define the value of TME in a general hospital population, we decided to include all patients of all ages

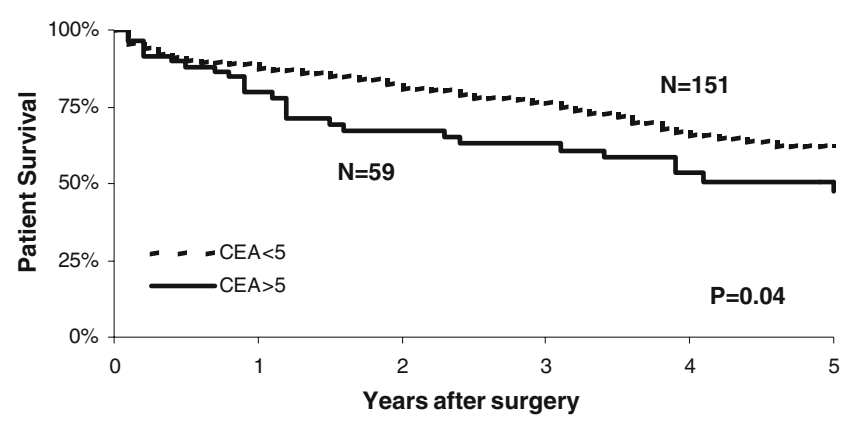

Fig. 3 Overall survival according to CEA $(P=0.04)$

with a potentially resectable rectal carcinoma. Evaluation of the results, therefore, includes patients previously treated by local transanal resection and patients with postoperatively proven T4 tumors and elderly patients or patients who are not fit enough to enter clinical trials. Bearing this in mind, our results are encouraging. The local recurrence rate was $13 \%$ in the whole group at 5 years, including patients with and without preoperative radiotherapy. When considering the microscopically complete resected tumors, the recurrence rate was $9 \%$. R1 resections showed a $21 \%$ local recurrence rate, which is similar to what has been described in the literature [17, 19]. Adequate surgery plays a key role in preventing local recurrences $[20,21]$. Quirke showed a linear correlation between the development of a local recurrence and an inadequate resection with positive circumferential margins $[14,22]$. It is, therefore, of crucial importance to optimize preoperative work-up to identify those patients who will need preoperative treatment in order to downsize and downstage the tumor. In our study, four patients with a local recurrence proved to have T4 tumors, which were not preoperatively correctly diagnosed and, therefore, did not undergo preoperative chemoradiotherapy. New imaging techniques using MRI to stage these tumors accurately will improve this in the future [23-27].

The use of sharp perimesorectal dissection and the practice of "close shave" anterior resection has not only led to fewer recurrences but also increased the sphincter saving rate. Heald et al. [28] reported that APR was required in $23 \%$ of patients with tumors in the lower rectum. In the present study, an APR was performed in 30\%
Table 5 Results of the multivariate Cox regression analysis for local recurrence and overall survival

$H R$ hazard ratio, $95 \% C I 95 \%$ confidence interval

\begin{tabular}{|c|c|c|c|c|c|c|}
\hline & \multicolumn{3}{|c|}{ Local recurrence } & \multicolumn{3}{|c|}{ Overall survival } \\
\hline & HR & $95 \% \mathrm{CI}$ & $P$ value & HR & $95 \% \mathrm{CI}$ & $P$ value \\
\hline Type of resection-APR & 0.20 & $0.1-0.5$ & 0.000 & 0.74 & $0.4-1.2$ & 0.284 \\
\hline Lymph nodes-positive & 3.63 & $1.5-8.9$ & 0.005 & 1.99 & $1.2-3.3$ & 0.007 \\
\hline Completeness - incomplete & 0.00 & $0.00-100+$ & 0.000 & 1.01 & $0.4-2.5$ & 0.981 \\
\hline Level of $\mathrm{CEA} \longrightarrow 5$ & 2.05 & $0.8-4.9$ & 0.105 & 1.83 & $1.1-3.0$ & 0.019 \\
\hline Age $\longrightarrow 80$ & - & - & - & 2.76 & $1.5-5.0$ & 0.000 \\
\hline
\end{tabular}


of the patients. Since there is a significantly worse outcome on both local control and overall survival and the high rate of perineal complications in patients with an APR pretreated with preoperative radiotherapy, it is favorable to have fewer APR [8].

Anastomotic leakage is a major complication associated with TME. As the risk of leakage depends on the level of the anastomosis, the incidence of leakage is high following TME in low rectal tumors (7-9\%) [29]. A total of eight patients $(5 \%)$ in our study developed an anastomotic leakage. Six of them $(75 \%)$ were located in patients with very low anastomoses (below $5 \mathrm{~cm}$ ), which increases the risk for leakage. All these patients had been treated with preoperative radiotherapy, which is known to increase the risk for leakage [30-32].

The prognosis in our patient series is similar to other reported data, showing an overall survival of more than $60 \%$ after 5 years $[33,34]$. To identify prognostic factors, a univariate analysis was included. As expected, TNM classification was of significant importance for prognosis [17]. As reported by many others [8, 11, 13, 35-39], completeness of the resection was also a significant prognostic factor. New treatment protocols (neoadjuvant chemoradiation) and meticulous preoperative work-up will possibly lead to more complete resections in the future. Furthermore, in contrast with previous reports [40], high levels of CEA levels were of significant importance on both overall survival and local recurrence in the present study [41-44]. Age $>80$ was also an important factor for a decreased overall survival in the present study. After 5 years, the overall survival of patients above 80 was $30 \%$ compared to $64 \%$ in patients under the age of 80 . The incidence of comorbidity, which renders the patient vulnerable to postoperative complications, is also highest after this age $[45,46]$. After major resectional treatment, elderly patients with rectal cancer have an increased 30-day and 6-month mortality compared with younger patients. Treatment-related mortality is an important competitive risk factor, which obscures the positive effect of modern rectal cancer treatment in those aged 75 years and above [37, 46-48].

In conclusion, TME is a feasible technique with an acceptable rate of postoperative morbidity and low mortality also in a community hospital. Patients with positive lymph nodes, an incomplete resection, aged above 80 , and/or a high level of CEA have a poor prognosis. Meticulous preoperative work-up is of great importance to decrease incomplete resections and improve results in future patients.

Open Access This article is distributed under the terms of the Creative Commons Attribution Noncommercial License which permits any noncommercial use, distribution, and reproduction in any medium, provided the original author(s) and source are credited.

\section{References}

1. Vermaas M, Ferenschild FT, Nuyttens JJ et al (2005) Preoperative radiotherapy improves outcome in recurrent rectal cancer. Dis Colon Rectum 48:918-928

2. Kapiteijn E, Marijnen CA, Colenbrander AC et al (1998) Local recurrence in patients with rectal cancer diagnosed between 1988 and 1992: a population-based study in the west Netherlands. Eur J Surg Oncol 24:528-535

3. Heald RJ, Husband EM, Ryall RD (1982) The mesorectum in rectal cancer surgery-the clue to pelvic recurrence? Br J Surg 69:613-616

4. Heald RJ, Ryall RD (1986) Recurrence and survival after total mesorectal excision for rectal cancer. Lancet 1:1479-1482

5. MacFarlane JK, Ryall RD, Heald RJ (1993) Mesorectal excision for rectal cancer. Lancet 341:457-460

6. Quirke P, Dixon MF (1988) The prediction of local recurrence in rectal adenocarcinoma by histopathological examination. Int $\mathrm{J}$ Colorectal Dis 3:127-131

7. Anonymous (1997) Swedish Rectal Cancer Trial. Improved survival with preoperative radiotherapy in resectable rectal cancer. N Engl J Med 336:980-987

8. Kapiteijn E, Marijnen CA, Nagtegaal ID et al (2001) Preoperative radiotherapy combined with total mesorectal excision for resectable rectal cancer. N Engl J Med 345:638-646

9. Nagtegaal ID, van de Velde CJ, Marijnen CA, van Krieken JH, Quirke P (2005) Low rectal cancer: a call for a change of approach in abdominoperineal resection. J Clin Oncol 23:9257-9264

10. Peeters KC, van de Velde CJ, Leer JW et al (2005) Late side effects of short-course preoperative radiotherapy combined with total mesorectal excision for rectal cancer: increased bowel dysfunction in irradiated patients - a Dutch colorectal cancer group study. J Clin Oncol 23:6199-6206

11. Peeters KC, Marijnen CA, Nagtegaal ID et al (2007) The TME trial after a median follow-up of 6 years: increased local control but no survival benefit in irradiated patients with resectable rectal carcinoma. Ann Surg 246:693-701

12. Kapiteijn E, van de Velde CJ (2002) Developments and quality assurance in rectal cancer surgery. Eur J Cancer 38:919-936

13. Debes AJ, Storkson RH, Jacobsen MB (2008) Curative rectal cancer surgery in a low-volume hospital: a quality assessment. Eur J Surg Oncol 34:382-389

14. Quirke P, Durdey P, Dixon MF, Williams NS (1986) Local recurrence of rectal adenocarcinoma due to inadequate surgical resection. Histopathological study of lateral tumour spread and surgical excision. Lancet 2:996-999

15. Martling AL, Holm T, Rutqvist LE, Moran BJ, Heald RJ, Cedemark B (2000) Effect of a surgical training programme on outcome of rectal cancer in the County of Stockholm. Stockholm Colorectal Cancer Study Group, Basingstoke Bowel Cancer Research Project. Lancet 356:93-96

16. Ferenschild FT, Vermaas M, Nuyttens JJ et al (2006) Value of intraoperative radiotherapy in locally advanced rectal cancer. Dis Colon Rectum 49:1257-1265

17. Law WL, Chu KW (2004) Anterior resection for rectal cancer with mesorectal excision: a prospective evaluation of 622 patients. Ann Surg 240:260-268

18. Piso P, Dahlke MH, Mirena P et al (2004) Total mesorectal excision for middle and lower rectal cancer: a single institution experience with 337 consecutive patients. J Surg Oncol 86:115-121

19. Arenas RB, Fichera A, Mhoon D, Michelassi F (1998) Total mesenteric excision in the surgical treatment of rectal cancer: a prospective study. Arch Surg 133:608-611 discussion 611-612

20. Havenga K, Enker WE, Norstein J et al (1999) Improved survival and local control after total mesorectal excision or D3 lymphade- 
nectomy in the treatment of primary rectal cancer: an international analysis of 1411 patients. Eur J Surg Oncol 25:368-374

21. Moore E, Heald RJ, Cecil TD, Sharpe GD, Sexton R, Moran BJ (2005) Almost all five year disease free survivors are cured following rectal cancer surgery, but longer term followup detects some late local and systemic recurrences. Colorectal Dis 7:403-405

22. Nagtegaal ID, van de Velde CJ, van der Worp E, Kapiteijn E, Quirke P, van Krieken JH (2002) Macroscopic evaluation of rectal cancer resection specimen: clinical significance of the pathologist in quality control. J Clin Oncol 20:1729-1734

23. Vliegen RF, Beets GL, von Meyenfeldt MF et al (2005) Rectal cancer: MR imaging in local staging - is gadolinium-based contrast material helpful? Radiology 234:179-188

24. Lahaye MJ, Engelen SM, Nelemans PJ et al (2005) Imaging for predicting the risk factors - the circumferential resection margin and nodal disease - of local recurrence in rectal cancer: a metaanalysis. Semin Ultrasound CT MR 26:259-268

25. Beets-Tan RG, Vliegen RF, Beets GL (2004) Magnetic resonance imaging of rectal cancer: what radiation oncologists need to know. Front Radiat Ther Oncol 38:1-12

26. Beets-Tan RG, Lettinga T, Beets GL (2005) Pre-operative imaging of rectal cancer and its impact on surgical performance and treatment outcome. Eur J Surg Oncol 31:681-688

27. de Lussanet QG, Backes WH, Griffioen AW et al (2005) Dynamic contrast-enhanced magnetic resonance imaging of radiation therapy-induced microcirculation changes in rectal cancer. Int J Radiat Oncol Biol Phys 63:1309-1315

28. Heald RJ, Smedh RK, Kald A, Sexton R, Moran BJ (1997) Abdominoperineal excision of the rectum - an endangered operation. Norman Nigro Lectureship. Dis Colon Rectum 40:747-751

29. Vignali A, Fazio VW, Lavery IC et al (1997) Factors associated with the occurrence of leaks in stapled rectal anastomoses: a review of 1, 014 patients. J Am Coll Surg 185:105-113

30. Lee WS, Yun SH, Roh YN et al (2008) Risk factors and clinical outcome for anastomotic leakage after total mesorectal excision for rectal cancer. World J Surg 32:1124-1129

31. Jestin P, Pahlman L, Gunnarsson U (2008) Risk factors for anastomotic leakage after rectal cancer surgery: a case-control study. Colorectal Dis 10:715-21

32. Matthiessen P, Hallbook O, Andersson M, Rutegard J, Sjodahl R (2004) Risk factors for anastomotic leakage after anterior resection of the rectum. Colorectal Dis 6:462-469

33. Wibe A, Syse A, Andersen E, Tretli S, Myrvold HE, Soreide O (2004) Oncological outcomes after total mesorectal excision for cure for cancer of the lower rectum: anterior vs. abdominoperineal resection. Dis Colon Rectum 47:48-58

34. Enker WE (1999) Mesorectal excision (TME) in the operative treatment of rectal cancer. Int J Surg Investig 1:253-255
35. Gunderson LL, Sargent DJ, Tepper JE et al (2004) Impact of T and $\mathrm{N}$ stage and treatment on survival and relapse in adjuvant rectal cancer: a pooled analysis. J Clin Oncol 22:1785-1796

36. Huh JW, Jung EJ, Park YA, Lee KY, Sohn SK (2008) Sphincterpreserving operations following preoperative chemoradiation: an alternative to abdominoperineal resection for lower rectal cancer? World J Surg 32:1116-1123

37. Law WL, Choi HK, Ho JW, Lee YM, Seto CL (2006) Outcomes of surgery for mid and distal rectal cancer in the elderly. World J Surg 30:598-604

38. Marijnen CA, Nagtegaal ID, Kapiteijn E et al (2003) Radiotherapy does not compensate for positive resection margins in rectal cancer patients: report of a multicenter randomized trial. Int J Radiat Oncol Biol Phys 55:1311-1320

39. Nissan A, Stojadinovic A, Shia J et al (2006) Predictors of recurrence in patients with T2 and early T3, N0 adenocarcinoma of the rectum treated by surgery alone. J Clin Oncol 24:4078-4084

40. Wiig JN, Larsen SG, Dueland S, Giercksky KE (2008) Preoperative irradiation and surgery for local recurrence of rectal and rectosigmoid cancer. Prognostic factors with regard to survival and further local recurrence. Colorectal Dis 10:48-57

41. Grossmann I, de Bock GH, Meershoek-Klein Kranenbarg WM, van de Velde CJ, Wiggers T (2007) Carcinoembryonic antigen (CEA) measurement during follow-up for rectal carcinoma is useful even if normal levels exist before surgery. A retrospective study of CEA values in the TME trial. Eur J Surg Oncol 33:183-187

42. Reiter W, Stieber P, Reuter C, Nagel D, Lau-Werner U, Lamerz R (2000) Multivariate analysis of the prognostic value of CEA and CA 19-9 serum levels in colorectal cancer. Anticancer Res 20:5195-5198

43. Louhimo J, Carpelan-Holmstrom M, Alfthan H, Stenman UH, Jarvinen HJ, Haglund C (2002) Serum HCG beta, CA 72-4 and $\mathrm{CEA}$ are independent prognostic factors in colorectal cancer. Int $\mathrm{J}$ Cancer 101:545-548

44. Carpelan-Holmstrom M, Louhimo J, Stenman UH, Alfthan H, Jarvinen H, Haglund C (2004) CEA, CA 242, CA 19-9, CA 72-4 and hCGbeta in the diagnosis of recurrent colorectal cancer. Tumour Biol 25:228-234

45. Lemmens VE, Janssen-Heijnen ML, Verheij CD, Houterman S, van Driel OJ Repelaer, Coebergh JW (2005) Co-morbidity leads to altered treatment and worse survival of elderly patients with colorectal cancer. Br J Surg 92:615-623

46. Rutten HJ, den Dulk M, Lemmens VE, van de Velde CJ, Marijnen CA (2008) Controversies of total mesorectal excision for rectal cancer in elderly patients. Lancet Oncol 9:494-501

47. Endreseth BH, Romundstad P, Myrvold HE, Bjerkeset T, Wibe A (2006) Rectal cancer treatment of the elderly. Colorectal Dis 8:471-479

48. Larsen SG, Wiig JN, Tretli S, Giercksky KE (2006) Surgery and pre-operative irradiation for locally advanced or recurrent rectal cancer in patients over 75 years of age. Colorectal Dis 8:177-185 